\title{
Impact of Vendor Computerized Physician Order Entry on Patients With Renal Impairment in Community Hospitals
}

\author{
Alexander A. Leung, MD, MPH${ }^{1}$, Gordon Schiff, MD¹, Carol Keohane, BSN, RN¹ , Mary Amato, PharmD, MPH ${ }^{1,2}$, \\ Steven R. Simon, MD, MPH${ }^{1}$, Bismarck Cadet, MD³, Michael Coffey, MD4, Nathan Kaufman, MD², Eyal Zimlichman, MD¹, \\ Diane L. Seger, RPh${ }^{1}$, Catherine Yoon, $\mathrm{MS}^{1}$, David W. Bates, MD, MSc ${ }^{1 *}$
}

\begin{abstract}
'Division of General Medicine and Primary Care, Department of Medicine, Brigham and Women's Hospital, Boston, Massachusetts; ' 2 Massachusetts College of Pharmacy and Health Sciences, Boston, Massachusetts; ${ }^{3}$ New England Inpatient Specialists, Methuen, Massachusetts; ${ }^{4}$ Partners Community Healthcare, Inc., Needham, Massachusetts.
\end{abstract}

BACKGROUND: Adverse drug events (ADEs) are common among hospitalized patients with renal impairment.

OBJECTIVE: To determine whether computerized physician order entry (CPOE) systems with clinical decision support capabilities reduce the frequency of renally related ADEs in hospitals.

DESIGN, SETTING, AND PATIENTS: Quasi-experimental study of 1590 adult patients with renal impairment who were admitted to 5 community hospitals in Massachusetts from January 2005 to September 2010, preimplementation and postimplementation of CPOE.

INTERVENTION: Varying levels of clinical decision support, ranging from basic CPOE only (sites 4 and 5), rudimentary clinical decision support (sites 1 and 2), and advanced clinical decision support (site 3).

MEASUREMENTS: Primary outcome was the rate of preventable ADEs from nephrotoxic and/or renally cleared medications. Similarly, secondary outcomes were the rates of overall ADEs and potential ADEs.
KEY RESULTS: There was a $45 \%$ decrease in the rate of preventable ADEs following implementation (8.0/100 vs $4.4 / 100$ admissions; $P<0.01$ ), and the impact was related to the level of decision support. Basic CPOE was not associated with any significant benefit (4.6/100 vs $4.3 / 100$ admissions; $P=0.87$ ). There was a nonsignificant decrease in preventable ADEs with rudimentary clinical decision support $(9.1 / 100$ vs $6.4 / 100$ admissions; $P=0.22$ ). However, substantial reduction was seen with advanced clinical decision support (12.4/100 vs 0/100 admissions; $P=0.01$ ). Despite these benefits, a significant increase in potential ADEs was found for all systems (55.5/100 vs $136.8 / 100$ admissions; $P<0.01)$.

CONCLUSION: Vendor-developed CPOE with advanced clinical decision support can reduce the occurrence of preventable ADEs but may be associated with an increase in potential ADEs. Journal of Hospital Medicine 2013;8:545-552. (c) 2013 Society of Hospital Medicine
Hospitalized patients with renal impairment are vulnerable to adverse drug events (ADEs). ${ }^{1,2}$ Appropriate prescribing for patients with renal insufficiency is challenging because of the complexities of drug therapy within the wide spectrum of kidney disease. ${ }^{3-6}$ Accordingly, computerized physician order entry (CPOE) systems with clinical decision support may help prevent many ADEs by providing timely laboratory information, recommending renally adjusted doses, and by offering assistance with prescribing. ${ }^{7-9}$

Despite the proposed benefits of CPOE, outcomes vary greatly because of differences in technology. ${ }^{10-13}$ In particular, the type of decision support available to assist medication ordering in the setting of renal dis-

*Address for correspondence and reprint requests: David W. Bates, MD, Chief, Division of General Internal Medicine and Primary Care, Brigham and Women's Hospital, One Brigham Circle, 1620 Tremont St., 3rd Floor, Boston, MA 02120-1613; Telephone: 617-732-5650; Fax: 617732-7072; E-mail: dbates@partners.org

Additional Supporting Information may be found in the online version of this article.

Revised: June 7, 2013; Accepted: June 11, 2013

2013 Society of Hospital Medicine DOI 10.1002/jhm.2072

Published online in Wiley Online Library (Wileyonlinelibrary.com). ease varies widely among current vendor systems. Given the uncertain benefits of CPOE, especially with the wide range of associated clinical decision support, we conducted this study to determine the impact of these systems on the rates of ADEs among hospitalized patients with kidney disease.

\section{METHODS}

This study was approved by the institutional review boards at each study site.

\section{Design and Setting}

We conducted a before-and-after study to evaluate the impact of newly implemented vendor CPOE systems in 5 community hospitals in Massachusetts. Although we reported on 6 hospitals in our baseline study, ${ }^{14} 1$ of these hospitals later chose not to implement CPOE, and therefore was not included in follow-up. At the time of this study, 1 of the hospitals (site 3) had not yet achieved hospital-wide implementation. Although CPOE had been adopted by most medical services at site 3, it had not yet been implemented in the emergency, obstetrical, or surgical departments. Thus, we limited our study to the medical services at this site. For the remaining sites, all admitting services were 
included with the exception of the psychiatric and neonatal services, which were excluded from both phases because they would have required different detection tools.

\section{Participants}

Patients aged $\geq 18$ years with renal failure, exposed to potentially nephrotoxic and/or renally cleared medications, and admitted to any of the participating hospitals during the study period were eligible for inclusion. Of the patients meeting eligibility criteria, we randomly selected approximately 150 records per hospital in the preimplementation and postimplementation phases for a total sample of 1590 charts. The first phase of this study occurred from January 2005 to August 2006; the second phase began 6 months postimplementation and lasted from October 2008 to September 2010.

\section{Principal Exposure}

Each hospital independently selected a vendor CPOE system with variable clinical decision support capabilities: (1) sites 4 and 5 had basic CPOE only with no clinical decision support for renal disease; (2) sites 1 and 2 implemented rudimentary clinical decision support with laboratory display (eg, serum creatinine) whenever common renally related drugs were ordered; and (3) site 3 had the most advanced support in place where, in addition to basic order entry and lab checks, physicians were provided with suggested doses for renally cleared and/or nephrotoxic medications, as well as appropriate drug monitoring for medications with narrow therapeutic indices (eg, suggested dosages and frequencies for vancomycin and automated corollary laboratory monitoring).

\section{Definitions}

We screened for the presence of renal failure by a serum creatinine $\geq 1.5 \mathrm{mg} / \mathrm{dL}$ at the time of admission. However, the duration of renal impairment was not known. We defined 3 levels of renal insufficiency based on the calculated creatinine clearance $(\mathrm{CrCl})^{15}$ : mild ( $\mathrm{CrCl} \quad 50-80 \mathrm{~mL} / \mathrm{min})$, moderate (16-49 $\mathrm{mL} / \mathrm{min})$, and severe $(\leq 15 \mathrm{~mL} / \mathrm{min})$. Subjects with a $\mathrm{CrCl}>80 \mathrm{~mL} / \mathrm{min}$ were considered to have normal renal function and were excluded. Potentially nephrotoxic and/or renally cleared medications were then identified using an established knowledge base (see Supporting Information, Table 1, in the online version of this article). ${ }^{16}$

In both phases of our study, only medications that were potentially nephrotoxic and/or renally cleared were included as potential cases; all other drugs were excluded. We defined an ADE as any drugrelated injury. These were considered preventable if they were due to an error at the time of order entry (eg, a doubling of creatinine secondary to an overdose of gentamicin or failure to order corollary drug levels for monitoring). A nonpreventable ADE was any drug-related injury in which there was no error at the time of order entry (eg, a doubling of creatinine despite appropriate dosing of lisinopril). ${ }^{17}$ A medication error was an error anywhere in the process of prescribing, transcribing, dispensing, administering, or monitoring a drug, but with no potential for harm or injury (eg, an order for an oral medication with no route specified when it was clear that the oral route was intended). ${ }^{18}$ A potential ADE was an error with the potential to cause harm, but not resulting in injury, either because it was intercepted (eg, an order for ketorolac for a patient with renal failure, but caught by a pharmacist) or because of chance (eg, administering enoxaparin to a patient with severe renal dysfunction but without hemorrhage).

All study investigators underwent standardized training using a curriculum developed by the Center for Patient Safety Research and Practice (www.patientsafetyresearch.org) to standardize definitions and terminology, data collection methods, classification strategies, and maximize reproducibility. ${ }^{14,17,19-21}$ An instructional manual was provided along with examples. Training was reinforced using practice cases and quizzes.

\section{Main Outcome Measures}

The primary outcome was the rate of preventable ADEs. Secondary outcomes were the rates of potential ADEs and overall ADEs. All outcomes were related to nephrotoxicity or accumulation of a renally excreted medication.

Data collection and classification strategies were identical in both phases of our study. ${ }^{14}$ We reviewed physician orders, medication lists, laboratory reports, admission histories, progress and consultation notes, discharge summaries, and nursing flow sheets, screening for the presence of medication incidents using an adaptation of the Institute for Healthcare Improvement's trigger tool, selected for its high sensitivity, reproducibility, and ease of use. ${ }^{22,23}$ In our adaptation of the tool, we excluded lidocaine, tobramycin, amikacin, and theophylline levels because of their infrequency. For each trigger found, a detailed description of the incident was extracted for detailed review. An example of a trigger is the use of sodium polystyrene, which may possibly indicate an overdose of potassium or a medication side effect.

Subsequently, each case was then independently reviewed by two investigators (A.A.L., M.A., B.C., S.R.S., M.C., N.K., E.Z., and G.S.)—each assigned to at least 1 site-and blinded to prescribing physician and hospital to determine whether nephrotoxicity or injury from drug accumulation was present (see Supporting Information, Figure 1, in the online version of this article). ${ }^{17}$ First, incidents were classified as ADEs, potential ADEs, or medication errors 
TABLE 1. Baseline Characteristics

\begin{tabular}{|c|c|c|c|c|c|c|c|}
\hline \multirow[b]{2}{*}{ Baseline Characteristics } & \multirow[b]{2}{*}{ All Sites } & \multicolumn{5}{|c|}{ Hospital Site } & \multirow[b]{2}{*}{$P$ (Among All Sites) } \\
\hline & & 1 & 2 & 3 & 4 & 5 & \\
\hline No. of patients & 815 & 170 & 156 & 143 & 164 & 182 & - \\
\hline Age, y, mean (range) & $72.2(18.0-102.0)$ & $79.2(33-102)$ & $77.3(23-101)$ & $65.6(18-98)$ & $70.7(18-96)$ & $69.2(20-96)$ & $<0.01$ \\
\hline 18-44 years, no. (\%) & $68(9.1)$ & $1(0.67)$ & $8(6.5)$ & $20(14.9)$ & $15(9.4)$ & $24(13.4)$ & $<0.01$ \\
\hline 45-54 years, no. (\%) & $67(9.0)$ & $6(4.0)$ & $5(4.1)$ & 17 (12.7) & $16(10.0)$ & $23(12.9)$ & \\
\hline 55-64 years, no. (\%) & $79(10.6)$ & $15(10.0)$ & $12(9.8)$ & $23(17.2)$ & $13(8.1)$ & $16(8.9)$ & \\
\hline 65-74 years, no. (\%) & $104(13.9)$ & $20(13.3)$ & $12(9.8)$ & $16(11.9)$ & $30(18.8)$ & $26(14.5)$ & \\
\hline 75-84 years, no. (\%) & $197(26.4)$ & $44(29.3)$ & $36(29.3)$ & $24(17.9)$ & $49(30.6)$ & $44(24.6)$ & \\
\hline $\begin{array}{l}\geq 85 \text { years, no. }(\%) \\
\text { Sex }\end{array}$ & $231(31.0)$ & $64(42.7)$ & $50(40.7)$ & $34(25.4)$ & $37(23.1)$ & $46(25.7)$ & \\
\hline Male, no. (\%) & $427(57.0)$ & $66(44.0)$ & $60(48.8)$ & $82(60.7)$ & $105(65.2)$ & $114(63.7)$ & $<0.01$ \\
\hline Female, no. (\%) & $321(43.0)$ & $84(56.0)$ & $63(51.2)$ & $53(39.3)$ & $56(34.8)$ & $65(36.3)$ & \\
\hline \multicolumn{8}{|l|}{ Race } \\
\hline Caucasian, no. (\%) & $654(87.4)$ & $129(86.0)$ & $118(95.9)$ & $126(93.3)$ & $129(80.1)$ & $152(84.9)$ & $<0.01$ \\
\hline Hispanic, no. (\%) & $25(3.3)$ & $2(1.3)$ & $0(0)$ & $1(0.74)$ & $13(8.1)$ & $9(5.0)$ & \\
\hline African American, no. (\%) & $45(6.0)$ & $12(8.0)$ & $4(3.3)$ & $5(3.7)$ & $13(8.1)$ & $11(6.2)$ & \\
\hline Native American, no. (\%) & $0(0)$ & $0(0)$ & $0(0)$ & $0(0)$ & $0(0)$ & $0(0)$ & \\
\hline Asian, no. (\%) & $13(1.7)$ & $1(0.81)$ & $1(0.81)$ & $2(1.5)$ & $5(3.1)$ & $4(2.2)$ & \\
\hline Other, no. $(\%)$ & $7(0.94)$ & $2(1.3)$ & $0(0)$ & $1(0.74)$ & $1(14.3)$ & $3(1.7)$ & \\
\hline Not recorded, no. (\%) & $4(0.53)$ & $4(2.7)$ & $0(0)$ & $0(0.0)$ & $0(0)$ & $0(0)$ & \\
\hline \multicolumn{8}{|l|}{ Initial severity of renal dysfunction } \\
\hline Mild, CrCl 50-80 mL/min, no. (\%) & $60(7.4)$ & $4(2.4)$ & $5(3.2)$ & $5(3.5)$ & $14(8.5)$ & $32(17.6)$ & $<0.01$ \\
\hline Moderate, CrCl 16-49 mL/min, no. (\%) & $388(47.6)$ & $84(49.4)$ & $71(45.5)$ & $80(55.9)$ & $76(46.3)$ & $77(42.3)$ & \\
\hline Severe, $\mathrm{CrCl}<15 \mathrm{~mL} / \mathrm{min}$, no. $(\%)$ & $367(45.0)$ & $82(48.2)$ & $80(51.3)$ & $58(40.6)$ & $74(45.1)$ & $73(40.1)$ & \\
\hline LOS, d, median (IQR) & $4.0(2-6)$ & $4.0(3-7)$ & $3.0(2-5.5)$ & $4.0(2-7)$ & $4.0(2-7)$ & $4.0(2-6)$ & 0.02 \\
\hline DRG-weighted LOS, d, median (IQR) ${ }^{\dagger}$ & $5.0(3.7-6.7)$ & $5.5(4-6.7)$ & $5.0(3.4-6.2)$ & $5.6(4.3-6.7)$ & $5.0(3.3-6.7)$ & $5.0(4.2-6.7)$ & 0.27 \\
\hline
\end{tabular}

NOTE: Abbreviations: $\mathrm{CrCl}$, creatinine clearance; DRG, diagnosis-related group; IQR, interquartile range; $\mathrm{LOS}$, length of stay. For creatinine, multiply by a factor of 88.4 to convert from mg/dL to $\mu \mathrm{mol} / \mathrm{L}$

"One-way analysis of variance for continuous age; Fisher exact test for discrete variables. ${ }^{\dagger} \mathrm{DRG}$-weighted LOS based on 783/815 patients because of missing DRG codes for 32 patients.

with no potential for injury. Second, ADEs and potential ADEs were rated according to severity. When nephrotoxic drugs were ordered, event severity was classified according to the elevation in serum creatinine ${ }^{24}$ : increases of $\leq 10 \%$ were considered potential ADEs (near misses); increases of $10 \%$ to $100 \%$ were significant ADEs; and increases of $\geq 100 \%$ were serious ADEs. Changes in creatinine that were not associated with inappropriate medication orders were excluded. For renally excreted drugs with no potential for nephrotoxicity (eg, enoxaparin), we used clinical judgment to classify events as significant (eg, rash), severe (eg, 2-unit gastrointestinal bleed), life threatening (eg, transfer to an intensive care unit), or fatal categories, as based on earlier work. ${ }^{25}$ Disagreements were resolved by consensus. We had a $\mathrm{\kappa}$ score of $0.70(95 \%$ confidence interval $[\mathrm{CI}]: 0.61-0.80)$ for incident type, indicating excellent overall agreement.

\section{Statistical Analysis}

Baseline characteristics between hospitals were compared using the Fisher exact test for categorical variables and 1-way analysis of variance for continuous variables. The occurrence of each outcome was determined according to site. To facilitate comparisons between sites, rates were expressed as number of events per 100 admissions with 95\% CIs. To account for hospital effects in the analysis when comparing pre- and postimplementation rates of ADEs and potential ADEs, we developed a fixedeffects Poisson regression model. To explore the independent effects of each system, a stratified analysis was performed to compare average rates of each outcome observed.

\section{RESULTS}

The outcomes of 775 patients in the baseline study were compared with the 815 patients enrolled during the postimplementation phase. ${ }^{14}$ Among those in the postimplementation phase (Table 1), the mean age was 72.2 years, and they were predominantly male $(57.0 \%)$. The demographics of the patients admitted to each of the 5 sites varied widely $(P<0.01)$. Most patients had moderate to severe renal dysfunction.

Overall, the rates of ADEs were similar between the pre- and postimplementation phases $(8.9 / 100$ vs $8.3 / 100$ admissions, respectively; $P=0.74$ ) (Table 2 ). However, there was a significant decrease in the rate of preventable ADEs, the primary outcome of interest, following CPOE implementation (8.0/100 vs 4.4/100 admissions; $P<0.01$ ). A reduction in preventable ADEs was observed in every hospital except site 4, where only basic order entry was introduced. However, there was a significant increase in the rates of nonpreventable ADEs $(0.90 / 100$ vs 3.9/100 admissions; $P<0.01)$ and potential ADEs $(55.5 / 100$ vs 136.8/100 admissions; $P<0.01)$. 


\section{Stratified Analysis}

To account for differences in technology, we performed a stratified analysis (Table 3). As was consistent with the overall study estimates, the rates of nonpreventable ADEs and potential ADEs increased with all 3 interventions. In contrast, we found that the changes in preventable ADE rates were related to the level of clinical decision support, where the greatest benefit was associated with the most sophisticated decision support system $(P=0.03$ and 0.02 for comparisons between advanced vs rudimentary decision support and basic order entry only, respectively). There was no difference in preventable ADE rates at sites without decision support $(4.6 / 100$ vs $4.3 / 100$ admissions; $P=0.87$ ); with rudimentary clinical decision support, there was a trend toward a decrease in the preventable ADE rate, which did not meet statistical significance $(9.1 / 100$ vs $6.4 / 100$ admissions; $P=0.22)$, and, the greatest reduction was seen with advanced clinical decision support (12.4/100 vs $0 / 100$ admissions; $P<0.01$ ).

\section{Severity of Events}

We further analyzed our data based on event severity (Table 4). Among preventable ADEs, only 1 fatal event was observed, which occurred after CPOE implementation. Here, a previously opioid-naïve patient received intravenous morphine for malignant pain. Within the first 24 hours, the patient received $70.2 \mathrm{mg}$ of intravenous morphine, resulting in a decreased level of consciousness. The patient expired the following day. Furthermore, following implementation, among preventable ADEs, a reduction in significant events was seen $(P=0.02)$ along with a nonsignificant reduction in the rate of serious events $(P=0.06)$. However, the rate of preventable lifethreatening events was not different $(P=0.96)$. The nonpreventable ADE rate rose during the postimplementation period for both serious $(P=0.03)$ and significant events $(P<0.01)$. The risk of fatal and lifethreatening nonpreventable ADEs did not change. The potential ADE rate increased following implementation for all severities $(P<0.01)$.

\section{Case Reviews}

In total, there were 36 preventable ADEs identified during the postimplementation phase (Table 5). Of these, inappropriate renal dosing accounted for 26 preventable ADEs, which involved antibiotics (eg, gentamicin-induced renal failure), opioids (eg, over sedation from morphine), $\beta$-blockers (eg, hypotension from atenolol), angiotensin-converting enzyme inhibitors (eg, renal failure with hyperkalemia secondary to lisinopril), and digoxin (eg, bradyarrhythmia and toxicity). The use of contraindicated medications resulted in 7 preventable ADEs (eg, prescribing glyburide in the setting of severe renal impairment). ${ }^{26}$ The 
TABLE 3. Stratified Analysis by Level of Clinical Decision Support

\begin{tabular}{|c|c|c|c|c|c|c|c|c|c|}
\hline \multirow[b]{3}{*}{ Incident } & \multicolumn{9}{|c|}{ Rate per 100 Admissions by Level of Clinical Decision Support ( $95 \% \mathrm{Cl})$} \\
\hline & \multicolumn{3}{|c|}{ Basic CPOE Only (Sites 4 and 5) } & \multicolumn{3}{|c|}{ CPOE and Lab Display (Sites 1 and 2) } & \multicolumn{3}{|c|}{$\begin{array}{l}\text { CPOE, Lab Display, and Drug-Dosing } \\
\text { Check (Site 3) }\end{array}$} \\
\hline & Pre & Post & $P$ & Pre & Post & $P$ & Pre & Post & $P$ \\
\hline ADES & $5.6(3.4-8.7)$ & $9.5(6.6-13.2)$ & 0.08 & $10.3(7.3-14.3)$ & $8.9(6.0-12.5)$ & 0.55 & $12.4(7.53-19.1)$ & $4.2(1.7-8.5)$ & 0.02 \\
\hline Preventable & $4.6(2.6-7.5)$ & $4.3(2.5-6.9)$ & 0.87 & $9.1(6.3-12.8)$ & $6.4(4.1-9.6)$ & 0.22 & $12.4(7.53-19.1)$ & $0.00(0-0.03)$ & $<0.01$ \\
\hline Nonpreventable & $0.99(0.24-2.6)$ & $5.2(3.2-8.0)$ & $<0.01$ & $1.2(0.38-2.8)$ & $2.5(1.1-4.6)$ & 0.24 & $0.00(0-0.03)$ & $4.2(1.7-8.5)$ & $<0.01$ \\
\hline Potential ADES & $54.0(46.1-62.7)$ & $165.6(152.4-179.5)$ & $<0.01$ & $61.6(53.5-70.5)$ & $120.9(109.3-133.2)$ & $<0.01$ & $44.8(34.8-56.6)$ & $103.5(87.7-121.1)$ & $<0.01$ \\
\hline Intercepted & $1.7(0.59-3.6)$ & $2.9(1.4-5.1)$ & 0.30 & $2.7(1.3-4.9)$ & $3.1(1.5-5.4)$ & 0.76 & $1.4(0.23-4.3)$ & $2.8(0.87-6.5)$ & 0.42 \\
\hline Nonintercepted & $52.3(44.6-60.9)$ & $162.7(149.6-176.5)$ & $<0.01$ & $58.8(50.9-67.5)$ & $117.8(106.4-130.0)$ & $<0.01$ & $43.4(33.6-55.1)$ & $100.7(85.1-118.1)$ & $<0.01$ \\
\hline
\end{tabular}

NOTE: Abbreviations: ADEs, adverse drug events; CPOE, computerized physician order entry; Post, postimplementation; Pre, preimplementation.

remaining 3 preventable ADEs stemmed from unmonitored use of vancomycin.

\section{DISCUSSION}

We evaluated the use of vendor CPOE for hospitalized patients with renal disease and found that it was associated with a $45 \%$ reduction in preventable ADEs related to nephrotoxicity and accumulation of renally excreted medications. The impact of CPOE appeared to be related to the level of associated clinical decision support, where only the most advanced system was associated with benefit. We observed a significant increase in potential ADEs with all levels of intervention. Overall, these findings suggest that vendordeveloped applications with appropriate decision support can reduce the occurrence of renally related preventable ADEs, but careful implementation is needed if the potential ADE rate is to fall.

Many of the benefits of CPOE come from clinical decision support. ${ }^{11}$ When applied to patients with renal impairment, CPOE with clinical decision support has been associated with decreased lengths of stay, ${ }^{16,27}$ reduced use of contraindicated medications, ${ }^{28-30}$ improved dosing and drug monitoring, ${ }^{16,31,32}$ and improved general prescribing practices. ${ }^{29,33}$ Even so, the observed benefit of CPOE on ADE rates has been variable, with some studies reporting reductions, ${ }^{27,34}$ whereas others are unable to detect differences. ${ }^{16,31}$ These studies, however, limited their case definition of ADEs to strictly declining renal function, ${ }^{16,31,34}$ or adverse events directly resulting from anti-infective drugs. ${ }^{27}$ In contrast, our study accounted for nephrotoxicity and systemic toxicity from drug accumulation. Using this broader definition, we were able to detect large reductions in the rates of preventable ADEs following CPOE adoption.

Successful decision support is simple, intuitive, and provides speedy information that integrates seamlessly into the clinical workflow. ${ }^{35,36}$ However, information delivery, although necessary, is insufficient for improving safety. For instance, passive alerts are often ignored, deferred, or overridden. ${ }^{30,37,38}$ Demonstrating this, Quartarolo et al. found that informing physicians of the presence of renal impairment using automated reporting of glomerular filtration rates did not change prescribing behavior. ${ }^{39}$ In contrast, providing active feedback (with dosing recommendations) was observed to be more useful in effecting change. ${ }^{40}$ Chertow et al. further showed that providing an adjusted dose list with a default dose and frequency at the time of order entry for patients with renal insufficiency improved appropriate ordering and was associated with a decreased length of stay. ${ }^{16}$ Altogether, these studies help to explain why only CPOE with clinical decision support equipped to provide renally adjusted dosing and monitoring was associated with a reduction in preventable ADEs in our study.

However, in contrast to reports of internally developed systems, ${ }^{20,25}$ potential ADE rates actually rose during the follow-up portion of our study. These appeared to be chiefly related to customized order sets with the potential of overdosing drugs through therapeutic duplication, a problem that is commonly known to be associated with CPOE (ie, new orders that overlap with other new or active medication orders, which may be the same drug itself or from within the same drug class, with the risk of overdose). ${ }^{41,42}$ Of note, our findings give rise to several key implications. First, hospitals implementing vendor-developed $\mathrm{CPOE}$ systems may be at greater risk of incurring potential ADEs compared to those using home-grown systems, which have comparatively gone through more cycles of internal refinement. As such, it is necessary to monitor for issues postimplementation and respond with appropriate changes to achieve successful system performance. ${ }^{35,36}$ Second, although the rate of potential ADEs (near misses) increased, preventable ADEs decreased because some of these errors were intercepted, whereas others were averted simply because of chance. Of note, not all potential ADEs have the same potential for injury; more serious cases are more likely to result in actual ADEs (eg, failure to renally dose acetaminophen likely poses less potential for harm than prescribing a full dose of enoxaparin in the setting of severe renal failure). Third, we found that most potential ADEs could 
TABLE 4. Severity of Events

\begin{tabular}{|c|c|c|c|c|c|}
\hline \multirow[b]{2}{*}{ Incident } & \multicolumn{2}{|r|}{ Preimplementation } & \multicolumn{2}{|r|}{ Postimplementation } & \multirow[b]{2}{*}{$P$} \\
\hline & No. (\%) & Average Rate/100 Admissions $(95 \% \mathrm{Cl})^{*}$ & No. (\%) & Average Rate/100 Admissions $(95 \% \mathrm{Cl})^{\star}$ & \\
\hline \multicolumn{6}{|l|}{ All ADES } \\
\hline Fatal & $0(0)$ & $0.00(0-0.0047)$ & $1(1.4)$ & $0.12(0.007-0.54)$ & 0.52 \\
\hline Life-threatening & $3(4.3)$ & $0.39(0.10-1.0)$ & $3(4.4)$ & $0.37(0.09-0.95)$ & 0.95 \\
\hline Serious & $34(49.3)$ & $4.4(3.1-6.0)$ & $32(47.1)$ & $3.9(2.7-5.4)$ & 0.65 \\
\hline Significant & $32(46.4)$ & $4.1(2.9-5.7)$ & $32(47.1)$ & $3.9(2.7-5.4)$ & 0.84 \\
\hline Total & $69(100)$ & $8.9(7.0-11.2)$ & $68(100)$ & $8.3(6.5-10.5)$ & 0.74 \\
\hline \multicolumn{6}{|l|}{ Preventable ADES } \\
\hline Fatal & $0(0)$ & $0.00(0-0.0047)$ & $1(2.7)$ & $0.00(0-0.0045)$ & 0.52 \\
\hline Life-threatening & $2(3.2)$ & $0.26(0.04-0.80)$ & $2(5.6)$ & $0.25(0.04-0.76)$ & 0.96 \\
\hline Serious & $31(50.0)$ & $4.0(2.8-5.6)$ & $19(52.8)$ & $2.3(1.4-3.5)$ & 0.06 \\
\hline Significant & $29(46.8)$ & $3.7(2.5-5.3)$ & $14(38.9)$ & $1.7(0.97-2.8)$ & 0.02 \\
\hline Total & $62(100)$ & $8.0(6.2-10.2)$ & $36(100)$ & $4.4(3.1-6.0)$ & $<0.01$ \\
\hline \multicolumn{6}{|l|}{ Nonpreventable ADEs } \\
\hline Fatal & $0(0)$ & $0.00(0-0.0047)$ & $0(0)$ & $0.00(0-0.0045)$ & NS \\
\hline Life-threatening & $1(14.2)$ & $0.13(0.007-0.57)$ & $1(3.1)$ & $0.12(0.007-0.54)$ & 0.97 \\
\hline Serious & $3(42.9)$ & $0.39(0.10-1.0)$ & $13(40.6)$ & $1.6(0.88-2.6)$ & 0.03 \\
\hline Significant & $3(42.9)$ & $0.39(0.10-1.0)$ & $18(56.3)$ & $2.2(1.3-3.4)$ & $<0.01$ \\
\hline Total & $7(100)$ & $0.90(0.39-1.7)$ & $32(100)$ & $3.9(2.7-5.4)$ & $<0.01$ \\
\hline \multicolumn{6}{|l|}{ All potential ADEs } \\
\hline Life-threatening & $5(1.2)$ & $0.65(0.23-1.4)$ & $33(3.0)$ & $4.0(2.8-5.6)$ & $<0.01$ \\
\hline Serious & $233(54.2)$ & $30.1(26.4-34.1)$ & $429(38.4)$ & $52.6(47.8-57.8)$ & $<0.01$ \\
\hline Significant & $192(44.6)$ & $24.8(21.4-28.4)$ & $653(58.6)$ & $80.1(74.1-86.4)$ & $<0.01$ \\
\hline Total & $430(100)$ & $55.5(50.4-60.9)$ & $1115(100)$ & $136.8(128.9-145.0)$ & $<0.01$ \\
\hline \multicolumn{6}{|c|}{ Intercepted potential ADES } \\
\hline Life-threatening & $0(0)$ & $0.00(0-0.0047)$ & $1(4.2)$ & $0.12(0.007-0.54)$ & 0.52 \\
\hline Serious & $5(31.2)$ & $0.65(0.23-1.4)$ & $13(54.2)$ & $1.6(0.88-2.6)$ & 0.09 \\
\hline Significant & $11(68.8)$ & $1.4(0.74-2.4)$ & $10(41.6)$ & $1.2(0.62-2.2)$ & 0.74 \\
\hline Total & $16(100)$ & $2.1(1.2-3.2)$ & $24(100)$ & $2.9(1.9-4.3)$ & 0.24 \\
\hline \multicolumn{6}{|c|}{ Nonintercepted potential ADES } \\
\hline Life-threatening & $5(1.2)$ & $0.65(0.23-1.4)$ & $32(2.9)$ & $3.9(2.7-5.4)$ & $<0.01$ \\
\hline Serious & $228(55.1)$ & $29.4(25.8-33.4)$ & $416(38.1)$ & $51.0(46.3-56.1)$ & $<0.01$ \\
\hline Significant & $181(43.7)$ & $23.4(20.1-26.9)$ & $643(58.9)$ & $78.9(73.0-85.2)$ & $<0.01$ \\
\hline Total & $414(100)$ & $53.4(48.4-58.7)$ & $1091(100)$ & $133.9(126.1-142.0)$ & $<0.01$ \\
\hline
\end{tabular}

have been averted with a combination of basic (dosing guidance and drug-drug interactions checks) and advanced decision support (medication-associated laboratory testing and drug-disease interactions). ${ }^{43}$ Therefore, further refinements to existing software are needed to maximize safety outcomes.

Our study has some limitations. This study was not a randomized controlled trial, and thus is subject to potential confounding. Although 6 hospitals were involved at the study inception, ${ }^{14}$ one of these hospitals eventually opted not to implement CPOE, and further declined to participate as a control site. Therefore, we cannot exclude confounding from secular trends because we had no contemporaneous control group. However, the introduction of $\mathrm{CPOE}$ was the main medication safety-oriented intervention during the study interval, thus arguing against major confounding by cointervention. Second, even though it is possible that classification bias may have been introduced between the preimplementation and postimplementation portions of our study, especially given the passage of time, it is unlikely. Study personnel underwent training using a curriculum designed to maintain continuity across projects, minimize individual variability, and optimize reproducibility in data collection and classification, as in a number of previous studies. ${ }^{14,17,19-21}$ Third, our study is limited by a heterogeneous intervention, as varying levels of decision support were introduced. However, this reflects usual practice and may be construed as a strength as we were able to describe the impact of different types of decision support. Fourth, we enrolled patients with a large spectrum of renal impairment, and our findings are not specific to any particular subgroup. However, our wide recruitment strategy also enhances the generalizability. Finally, our study was restricted to patients who were exposed to potentially nephrotoxic and/or renally cleared drugs. As such, we could not determine whether advanced decision support helped to eliminate the use of some potentially dangerous medications altogether, as these cases would have been excluded from our study. It is possible, therefore, that our study findings underestimate the true benefit of clinical decision support.

In conclusion, vendor $\mathrm{CPOE}$ implementation in 5 community hospitals was associated with a $45 \%$ 
TABLE 5. Adverse Drug Events by Drug Class

\begin{tabular}{|c|c|c|c|c|c|c|c|}
\hline \multirow[b]{2}{*}{ Drug Class } & \multicolumn{3}{|c|}{ ADEs, Preventable, No. (Rate per 100 Admissions) $^{*}$} & \multicolumn{3}{|c|}{ ADEs, Nonpreventable, No. (Rate per 100 Admissions) ${ }^{*}$} & \multirow[b]{2}{*}{ Drugs Involved } \\
\hline & Preimplementation & Postimplementation & $\begin{array}{l}P \text { (for Entire } \\
\text { Drug Class) }\end{array}$ & Preimplementation & Postimplementation & $\begin{array}{l}P \text { (for Drug } \\
\text { Class) }\end{array}$ & \\
\hline Cardiovascular & $20(2.6)$ & $18(2.2)$ & 0.63 & $4(0.52)$ & $16(2.0)$ & 0.02 & Atenolol, bumetanide, captopril, \\
\hline Diuretics & $1(0.13)$ & $2(0.25)$ & & $1(0.13)$ & $9(1.1)$ & & digoxin, furosemide, hydralazine, \\
\hline$\beta$-blockers & $0(0.00)$ & $2(0.25)$ & & $1(0.13)$ & & & hydrochlorothiazide, \\
\hline $\begin{array}{l}\text { ACE inhibitors and } \\
\text { ARBs }\end{array}$ & $16(2.1)$ & $10(1.2)$ & & $2(0.26)$ & $7(0.86)$ & & $\begin{array}{l}\text { lisinopril, } \\
\text { sotalol, spironolactone }\end{array}$ \\
\hline Antiarrhythmic & $3(0.39)$ & $3(0.37)$ & & & & & \\
\hline Vasodilator & $0(0.00)$ & $1(0.12)$ & & & & & \\
\hline Analgesics & $28(3.6)$ & $4(0.49)$ & 0.0002 & $1(0.13)$ & $5(0.61)$ & 0.15 & Acetaminophen and combination \\
\hline Narcotic & $13(1.7)$ & $4(0.49)$ & & $0(0.00)$ & $5(0.61)$ & & pills containing \\
\hline Non-narcotic & $15(1.9)$ & $0(0.00)$ & & $1(0.13)$ & 0 & & $\begin{array}{l}\text { acetaminophen: Percocet } \\
\text { (oxycodone and acetaminophen), } \\
\text { Tylenol \#3 (codeine and } \\
\text { acetaminophen), Vicodin } \\
\text { (hydrocodone and } \\
\text { acetaminophen), fentanyl, } \\
\text { hydrocodone, meperidine, } \\
\text { morphine, oxycodone }\end{array}$ \\
\hline Antibiotics & $8(1.0)$ & $13(1.6)$ & 0.33 & $1(0.13)$ & $9(1.1)$ & 0.04 & $\begin{array}{l}\text { Amikacin, ampicillin and } \\
\text { sulbactam, ciprofloxacin, } \\
\text { cefazolin, cefuroxime, } \\
\text { gatifloxacin, } \\
\text { gentamicin, levofloxacin, } \\
\text { metronidazole, piperacillin } \\
\text { and tazobactam, } \\
\text { tobramycin, vancomycin }\end{array}$ \\
\hline Neurotropic drugs & $2(0.26)$ & $0(0.00)$ & 0.28 & 0 & 0 & - & Lithium, midazolam \\
\hline Sedatives & $1(0.13)$ & $0(0.00)$ & & & & & \\
\hline Antipsychotics & $1(0.13)$ & $0(0.00)$ & & & & & \\
\hline Diabetes & 0 & $1(0.12)$ & 0.52 & 0 & $1(0.12)$ & 0.52 & Glipizide, glyburide \\
\hline Oral antidiabetics & 0 & $1(0.12)$ & & & $1(0.12)$ & & \\
\hline Other drugs & $4(0.52)$ & $0(0.00)$ & 0.13 & $1(0.13)$ & $1(0.12)$ & 0.97 & Allopurinol, famotidine \\
\hline Gastrointestinal drugs & $1(0.13)$ & $0(0.00)$ & & & & & \\
\hline Other & $3(0.39)$ & $0(0.00)$ & & 0 & $1(0.12)$ & & \\
\hline
\end{tabular}

NOTE: Abbreviations: ACE, angiotensin-converting enzyme; ADEs, adverse drug events; ARB, angiotensin II receptor blocker. ${ }^{*}$ Counted as 1 case per patient per drug. One patient may have several ADEs.

reduction in preventable $\mathrm{ADE}$ rates among patients with renal impairment. Measurable benefit was associated with advanced decision support capable of lab display, dosing guidance, and medication-associated laboratory testing. Although the potential benefits of CPOE systems are far reaching, achieving the desired safety benefits will require appropriate decision support, tracking of problems that arise, and systematic approaches to eliminating them.

\section{Acknowledgments}

The authors thank Kathy Zigmont, RN, and Cathy Foskett, RN (Brigham and Women's Hospital, Division of General Internal Medicine and Primary Care) for the chart review and data collection at the participating study sites.

Disclosures: The Rx Foundation and Commonwealth Fund supported the study. They commented on its design, but were not involved in data collection, data management, analysis, interpretation, or writing of the manuscript. Dr. Leung is supported by a Clinical Fellowship Award from Alberta Innovates Health Solutions and by a Fellowship Award from the Canadian Institutes for Health Research. Dr. Schiff received financial support from the FDA CPOE Task Order and the Commonwealth Fund. Ms. Keohane served as a consultant to the American College of Obstetrician and Gynecologists and as a reviewer for the VRQC Program. She received honoraria for a presentation on Patient Safety in 2010, sponsored by Abbott Nutrition International, and a lecture on Nurse Interruptions in Medication Administration by Educational Review Systems. Dr. Coffey received an honorarium from Meditech for speaking on social networking at Physician/CIO Forum in 2009. Dr. Kaufman participates in an advisory group with Siemens Medical Solutions. Dr. Zimlichman received support from the Rx Foundation and the Commonwealth Fund. Dr. Bates holds a minority equity position in the privately held company Medicalis, which develops Web-based decision support for radiology test ordering, and has served as a consultant to Medicalis. He serves as an advisor to Calgary Scientific, which makes technologies that enable mobility within electronic health records. He is on the clinical advisory board for Patient Safety Systems, which provides a set of approaches to help hospitals improve safety. He has received funding support from the Massachusetts Technology Consortium. Ms. Amato, Dr. Simon, Dr. Cadet, Ms. Seger, and Ms. Yoon have no disclosures relevant to this study.

\section{References}

1. Aronoff GR, Bennett WM, Berns JS. Drug Prescribing in Renal Failure: Dosing Guidelines for Adults and Children: American College of Physicians; 2007.

2. Ponticelli C, Graziani G. Management of drug toxicity in patients with renal insufficiency. Nat Rev Nephrol. 2010;6(6):317318.

3. Blix HS, Viktil KK, Moger TA, Reikvam A. Use of renal risk drugs in hospitalized patients with impaired renal function-an underestimated problem? Nephrol Dial Transplant. 2006;21(11):31643171.

4. Salomon L, Deray G, Jaudon MC, et al. Medication misuse in hospitalized patients with renal impairment. Int J Qual Health Care. 2003; 15(4):331-335. 
5. Hassan Y, Al-Ramahi RJ, Aziz NA, Ghazali R. Impact of a renal drug dosing service on dose adjustment in hospitalized patients with chronic kidney disease. Ann Pharmacother. 2009;43(10):1598-1605.

6. Gabardi S, Abramson S. Drug dosing in chronic kidney disease. Med Clin North Am. 2005;89(3):649-687.

7. Leape LL, Bates DW, Cullen DJ, et al. Systems analysis of adverse drug events. ADE Prevention Study Group. JAMA. 1995;274(1):35-43.

8. Bobb A, Gleason K, Husch M, Feinglass J, Yarnold PR, Noskin GA. The epidemiology of prescribing errors: the potential impact of computerized prescriber order entry. Arch Intern Med. 2004;164(7):785792 .

9. Lesar TS, Briceland L, Stein DS. Factors related to errors in medication prescribing. JAMA. 1997;277(4):312-317.

10. Koppel R, Metlay JP, Cohen A, et al. Role of computerized physician order entry systems in facilitating medication errors. JAMA. 2005; 293(10):1197-1203.

11. Metzger J, Welebob E, Bates DW, Lipsitz S, Classen DC. Mixed results in the safety performance of computerized physician order entry. Health Aff (Millwood). 2010;29(4):655-663.

12. Wolfstadt JI, Gurwitz JH, Field TS, et al. The effect of computerized physician order entry with clinical decision support on the rates of adverse drug events: a systematic review. J Gen Intern Med. 2008; 23(4):451-458.

13. Eslami S, de Keizer NF, Abu-Hanna A. The impact of computerized physician medication order entry in hospitalized patients-a systematic review. Int J Med Inform. 2008;77(6):365-376.

14. Hug BL, Witkowski DJ, Sox CM, et al. Occurrence of adverse, often preventable, events in community hospitals involving nephrotoxic drugs or those excreted by the kidney. Kidney Int. 2009;76(11):1192-1198.

15. Cockcroft DW, Gault MH. Prediction of creatinine clearance from serum creatinine. Nephron. 1976;16(1):31-41.

16. Chertow GM, Lee J, Kuperman GJ, et al. Guided medication dosing for inpatients with renal insufficiency. JAMA. 2001;286(22):28392844.

17. Morimoto T, Gandhi TK, Seger AC, Hsieh TC, Bates DW. Adverse drug events and medication errors: detection and classification methods. Oual Saf Health Care. 2004;13(4):306-314.

18. Bates DW, Boyle DL, Vander Vliet MB, Schneider J, Leape L. Relationship between medication errors and adverse drug events. $J$ Gen Intern Med. 1995;10(4):199-205.

19. Bates DW, Cullen DJ, Laird N, et al. Incidence of adverse drug events and potential adverse drug events. Implications for prevention. ADE Prevention Study Group. JAMA. 1995;274(1):29-34.

20. Bates DW, Leape LL, Cullen DJ, et al. Effect of computerized physician order entry and a team intervention on prevention of serious medication errors. JAMA. 1998;280(15):1311-1316.

21. Hug BL, Witkowski DJ, Sox CM, et al. Adverse drug event rates in six community hospitals and the potential impact of computerized physician order entry for prevention. J Gen Intern Med. 2010;25(1):31-38.

22. Rozich JD, Haraden CR, Resar RK. Adverse drug event trigger tool: a practical methodology for measuring medication related harm. Qual Saf Health Care. 2003;12(3):194-200.

23. Institute for Healthcare Improvement: IHI Trigger Tool for Measuring Adverse Drug Events. 2011. Available at: http://www.ihi.org/knowledge/Pages/Tools/TriggerToolforMeasuringAdverseDrugEvents.aspx. Accessed February 1, 2013.

24. Bonney SL, Northington RS, Hedrich DA, Walker BR. Renal safety of two analgesics used over the counter: ibuprofen and aspirin. Clin Pharmacol Ther. 1986;40(4):373-377.

25. Bates DW, Teich JM, Lee J, et al. The impact of computerized physician order entry on medication error prevention. J Am Med Inform Assoc. 1999;6(4):313-321.
26. Krepinsky J, Ingram AJ, Clase CM. Prolonged sulfonylurea-induced hypoglycemia in diabetic patients with end-stage renal disease. Am J Kidney Dis. 2000;35(3):500-505.

27. Evans RS, Pestotnik SL, Classen DC, et al. A computer-assisted management program for antibiotics and other antiinfective agents. $N$ Engl J Med. 1998;338(4):232-238.

28. Matsumura Y, Yamaguchi T, Hasegawa H, et al. Alert system for inappropriate prescriptions relating to patients' clinical condition. Methods Inf Med. 2009;48(6):566-573.

29. Field TS, Rochon P, Lee M, Gavendo L, Baril JL, Gurwitz JH. Computerized clinical decision support during medication ordering for long-term care residents with renal insufficiency. J Am Med Inform Assoc. 2009;16(4):480-485.

30. Galanter WL, Didomenico RJ, Polikaitis A. A trial of automated decision support alerts for contraindicated medications using computerized physician order entry. J Am Med Inform Assoc. 2005;12(3):269274.

31. Cox ZL, Nelsen CL, Waitman LR, McCoy JA, Peterson JF. Effects of clinical decision support on initial dosing and monitoring of tobramycin and amikacin. Am J Health Syst Pharm. 2011;68(7): 624-632.

32. Terrell KM, Perkins AJ, Hui SL, Callahan CM, Dexter PR, Miller DK. Computerized decision support for medication dosing in renal insufficiency: a randomized, controlled trial. Ann Emerg Med. 2010;56(6): 623-629.

33. Nightingale PG, Adu D, Richards NT, Peters M. Implementation of rules based computerised bedside prescribing and administration: intervention study. BMJ. 2000;320(7237):750-753.

34. Rind DM, Safran C, Phillips RS, et al. Effect of computer-based alerts on the treatment and outcomes of hospitalized patients. Arch Intern Med. 1994;154(13):1511-1517.

35. Bates DW, Kuperman GJ, Wang S, et al. Ten commandments for effective clinical decision support: making the practice of evidencebased medicine a reality. J Am Med Inform Assoc. 2003;10(6):523530 .

36. Chang J, Ronco C, Rosner MH. Computerized decision support systems: improving patient safety in nephrology. Nat Rev Nephrol. $2011 ; 7(6): 348-355$.

37. Oppenheim MI, Vidal C, Velasco FT, et al. Impact of a computerized alert during physician order entry on medication dosing in patients with renal impairment. Proc AMIA Symp. 2002:577-581.

38. McCoy AB, Waitman LR, Gadd CS, et al. A computerized provider order entry intervention for medication safety during acute kidney injury: a quality improvement report. Am J Kidney Dis. 2010;56(5): $832-841$.

39. Quartarolo JM, Thoelke M, Schafers SJ. Reporting of estimated glomerular filtration rate: effect on physician recognition of chronic kidney disease and prescribing practices for elderly hospitalized patients. J Hosp Med. 2007;2(2):74-78.

40. Falconnier AD, Haefeli WE, Schoenenberger RA, Surber C, MartinFacklam M. Drug dosage in patients with renal failure optimized by immediate concurrent feedback. J Gen Intern Med. 2001;16(6):369375 .

41. Wetterneck TB, Walker JM, Blosky MA, et al. Factors contributing to an increase in duplicate medication order errors after CPOE implementation. J Am Med Inform Assoc. 2011;18(6):774-782.

42. Leung AA, Keohane C, Amato M, et al. Impact of Vendor Computerized Physician Order Entry in Community Hospitals. J Gen Intern Med. 2012;27(7):801-807.

43. Kuperman GJ, Bobb A, Payne TH, et al. Medication-related clinical decision support in computerized provider order entry systems: a review. J Am Med Inform Assoc. 2007;14(1):29-40. 